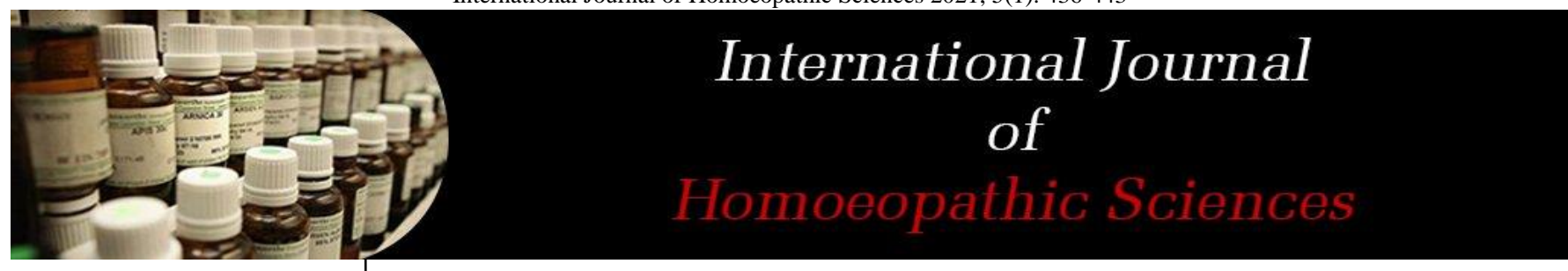

E-ISSN: $2616-4493$

P-ISSN: 2616-4485

www.homoeopathicjournal.com

IJHS 2021; 5(1): 436-443

Received: 24-12-2020

Accepted: 28-01-2021

Dr. Anupama Deshmukh Professor and HOD,

Department of Community

Medicine, Bhagawan Buddha

Homoeopathic Medical College and Hospital, Bengaluru,

Karnataka, India

\section{Vedhavathi A}

Final Year UG Scholar, Bhagawan Buddha

Homoeopathic Medical College and Hospital, Bengaluru,

Karnataka, India

BS Lakshmi

Final Year UG Scholar,

Bhagawan Buddha

Homoeopathic Medical College and Hospital, Bengaluru,

Karnataka, India

C. Jayasree

Final Year UG Scholar,

Bhagawan Buddha

Homoeopathic Medical College

and Hospital, Bengaluru,

Karnataka, India
Corresponding Author:

Dr. Anupama Deshmukh

Professor and HOD,

Department of Community

Medicine, Bhagawan Buddha

Homoeopathic Medical College

and Hospital, Bengaluru,

Karnataka, India

\section{Physical and psychological impact of smartphone usage during COVID lockdown: A survey review}

\section{Dr. Anupama Deshmukh, Vedhavathi A, BS Lakshmi and C Jayasree}

DOI: https://doi.org/10.33545/26164485.2021.v5.i1g.350

\section{Abstract}

The evolution of mobile phones just from a communication device to a device that supports multitasking is enormous. The recent technologies have contributed immensely to the development in the world of mobile phones. The features provided in the recent days have attracted the consumers to the extent of mobile addiction, which is a common problem today worldwide. The present study analyses the prevalence of smartphone usage and physical and psychological impacts in males and females on the basis of smartphone usage during the pandemic COVID-19 ${ }^{[6]}$

Keywords: COVID-19, lockdown, prevalence of smartphone usage, physical and psychological health, addiction

\section{Introduction}

Smartphone has brought out changes in the way of communication technology. It is estimated that in the next two years India's smartphone base would reach around 820 million. The usage of smartphones has been increased drastically among the urban as well as rural populations too, because of their amazing features which provide one stop solutions fulfilling the requirements. The impact of smartphones is such that they have created a greater business platform. It's just not about creating business platforms, but has led to a deadly cause of addiction ${ }^{[5,7]}$.

"Addiction is a condition of being unable to stop using or doing something as a habit, especially something harmful ${ }^{[8]}$ ".

Excessive usage of smartphones than required along with other activities is a manifestation of addiction. This can have adverse effects on the wellbeing of a person, both mentally and physically.

The American Psychiatric Association (APA, 2013) first categorized a behaviour-gamblingas a non-substance-related addictive disorder and recommends further research on Internet gaming disorder. However, at this time, no mention has been made of smartphone addiction in either the DSM-5 or in the ICD-11's draft. Nevertheless, research on smartphone and mobile phone addiction has notably increased in recent years (Aljomaa, Mohammad, Albursan, Bakhiet, \& Abduljabbar, 2016; Bian \& Leung, 2015; Chiu, 2014; Darcin et al., 2016; Demirci, Akgönül, \& Akpinar, 2015; Fu Yuan, Chiu, \& Huang, 2012; Haug et al., 2015; Hawi \& Samaha, 2016; Körmendi, Brutóczki, Végh, \& Székely, 2016; Leung, 2007; Lin et al., 2014; Lopez-Fernandez, 2015; Roberts, Pullig, \& Manolis, 2015; Salehan \& Negahban, 2013; Van Deursen, Bolle, Hegner, \& Kommers, 2015) and there seems to be a rising tendency to label popular technological behaviours as addictive ${ }^{[4]}$.

This pandemic-COVID-19, has bought in tremendous increase in the usage of smartphones for various purposes such as education, work, shopping, entertainment, health services, banking services, communication and so on

\section{Review of literature}

Smartphone usage increased considerably during lockdown period. The daily use duration of a smartphone is one of the most significant indicators of its impact on physical and psychological health.

Apart from communication, entertainment, the online classes increased the duration of smartphone usage. 
The causes of smartphone use can be attributed to the technological and content-related features of a smartphone along with accessibility, portability, easiness of operation, connectedness ${ }^{[2,12]}$.

\subsection{Impact on physical and psychological health}

Physical impacts range from Eyestrain, eyestrain, blurring of vision sleeplessness, tiredness, body ache, neck and wrist pain to obesity, male infertility due to radiation, seizures, brain tumours etc.

Psychological impacts are anxiety, negative emotions, depression, lack of concentration, restlessness. ${ }^{[9,13]}$

Problematic use can be assessed by the urge to check messages, activeness on social platforms, sleeping with smartphone under pillow and watching smartphone while eating ${ }^{[3,11]}$. It has also led to the interference with the daily activities and decreased productivity. ${ }^{[10]}$

Research question 1: What is the prevalence of smartphone usage in various age groups due to COVID lockdown?

Research question 2: Whether the high-risk group have more psychological and physical problems as compared with the normal user group?

\section{Method}

The study was conducted with the help of an online survey. Data was collected by a structured questionnaire which consisted of 27 questions focusing on all age groups.

Demographic variables were self-reported by participants and included age, sex, socioeconomic status, occupation, etc.

\subsection{Instrument}

Smartphone addiction questionnaire (SPAQ): This questionnaire was adopted and modified as per our needs from those in the article "Psychometric Properties of Smartphone Addiction Questionnaire (SPAQ) among Sultan Qaboos University Under graduate Students" published in journal of Educational and Psychological Studies- Sultan Qaboos University. Later the contents of the questionnaire were validated. The questionnaire was so framed to explore the level of smartphone addiction among various age groups through three parts ${ }^{[1]}$ :

1. The level of smartphone usage.

2. The purpose of usage.

3. The level of physical and psychological symptoms experienced.

The scoring was done based on the 10 questions which were related to the behaviours associated with problematic smartphone usage. The scores 5 and 1 were given for the responses YES and NO respectively. Based on the above scoring the respondents were categorized to high risk and normal groups considering the cut off score as 40 .

Later, the degree of negative impact of smartphone usage on one's daily routine, social life, productivity, sleeping patterns, feelings and physical health and impact of COVID lockdown on smartphone usage were assessed.

\section{Data analysis}

Of the 309 participants, $184(59.5 \%)$ were identified as high-risk group for smartphone addiction and 125 (40.4\%) were classified as a normal user group according to their scores.

\section{Demographic variables of the study are as follows}

Table 1: Smart phone usage in different age group

\begin{tabular}{|c|c|c|c|}
\hline Sl. No. & Age Group & No's & Percentage \\
\hline 1. & $1-10 \mathrm{yrs}$ & 4 & $1.29 \%$ \\
\hline 2. & $11-20 \mathrm{yrs}$ & 96 & $31.06 \%$ \\
\hline 3. & $21-30 \mathrm{yrs}$ & 175 & $56.63 \%$ \\
\hline 4. & $31-40 \mathrm{yrs}$ & 17 & $5.50 \%$ \\
\hline 5. & $41-50 \mathrm{yrs}$ & 8 & $2.58 \%$ \\
\hline 6. & $51-60 \mathrm{yrs}$ & 4 & $1.29 \%$ \\
\hline 7. & above $60 \mathrm{yrs}$ & 5 & $1.61 \%$ \\
\hline & Total & 309 & $100 \%$ \\
\hline
\end{tabular}

Smart phone usage was seen more among 21-30 years of age group [56.60\%] followed by 11-20 years [31.10\%]. In other age groups the usage was minimal.

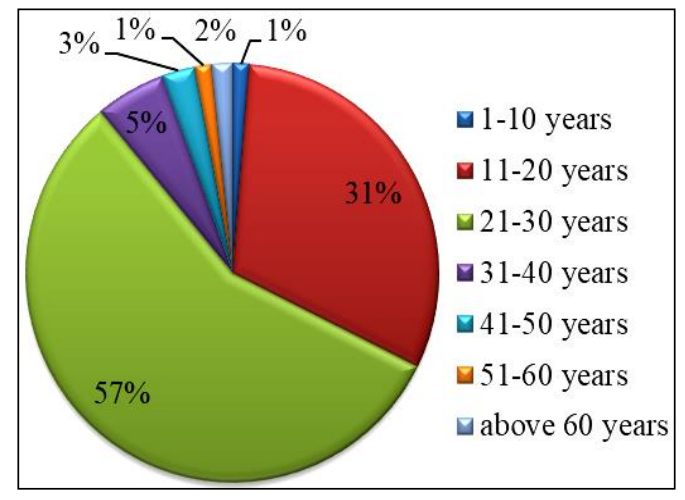

Fig 1: Smart phone usage in different age group
Table 2: Gender differences in smart phone usage

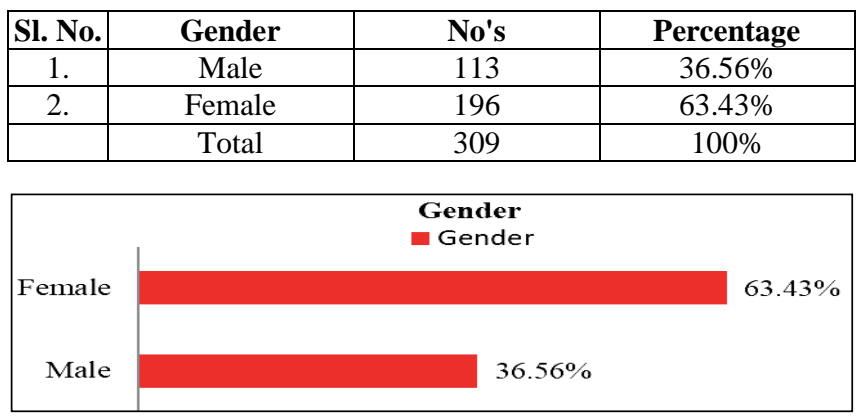

Fig 2: Gender differences in smart phone usage 
Table 3: Smart phone usage in various economic status

\begin{tabular}{|c|c|c|c|}
\hline Sl. No. & Economic status & No's & Percentage \\
\hline 1. & Lower class & 9 & $2.91 \%$ \\
\hline 2. & Middle class & 227 & $73.46 \%$ \\
\hline 3. & Upper middle class & 66 & $21.35 \%$ \\
\hline 4. & High class & 7 & $2.26 \%$ \\
\hline & Total & 309 & \\
\hline
\end{tabular}

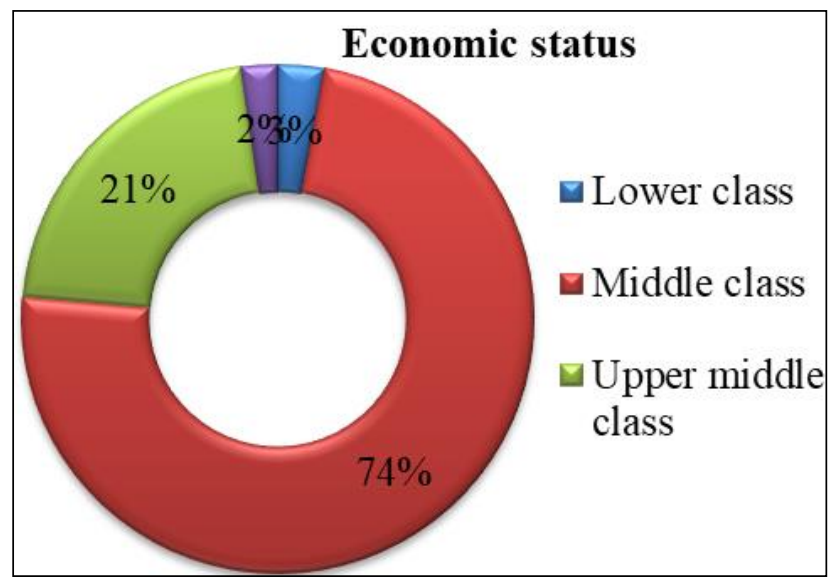

Fig 3: Smart phone usage in various economic statuses

Table 4: Smart phone usage in different occupations

\begin{tabular}{|c|c|c|c|}
\hline SI. No. & Occupation & No's & Percentage \\
\hline 1. & Students & 234 & $75.72 \%$ \\
\hline 2. & Non-working & 13 & $4.20 \%$ \\
\hline 3. & House wife & 11 & $3.55 \%$ \\
\hline 4. & Working & 51 & $16.50 \%$ \\
\hline & Total & 309 & \\
\hline
\end{tabular}

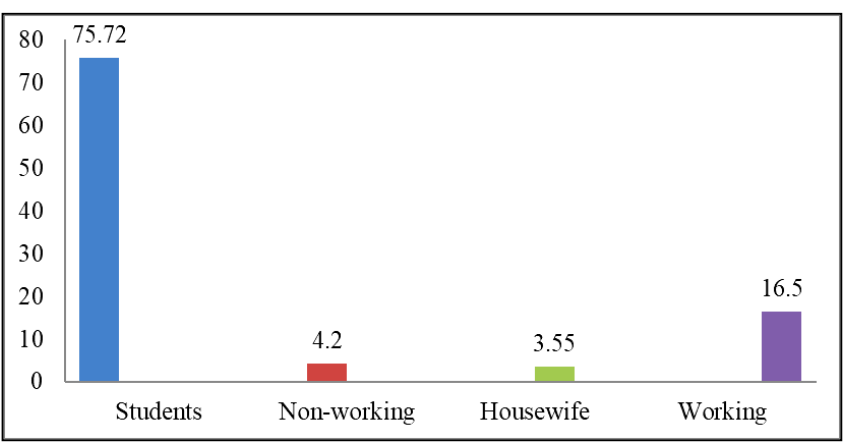

Fig 4: Smart phone usage in different occupations

Surprisingly the percentage of smart phone usage was high among females [63.4\%] than males [36.60\%] and the usage among middle class [73.50\%] was higher than upper middle class [21.40\%]. During the pandemic it was the student community whose smartphone usage was more [75.70\%] than working population [16.50\%].

The respondents were asked about the time spent on usage of smartphone and the purpose of usage along with the discomforts and ailments experienced [physical \& psychological] from the use of smartphone; measures taken by them to reduce the usage of smartphone.
The No. of hours spent more than 5 hours on smart phone among high-risk group was $45.6 \%$ compared to $19.2 \%$ among normal usage group. [Table 5]

During lockdown, the participants used their smart phone for communication like phone calls/messaging $81.5 \%$ among high risk and $72 \%$ among normal usage followed by the usage of social media was $76.6 \%$ among high risk, $64.8 \%$ in normal usage. Majority of the participants gave positive response [79\%] to effect of lockdown on smart phone usage.

Table 5: Level of usage

\begin{tabular}{|c|c|c|c|c|}
\hline $\begin{array}{c}\text { No. of hours } \\
\text { spent }\end{array}$ & $\begin{array}{c}\text { High risk } \\
\text { group n= } \\
\mathbf{1 8 4}\end{array}$ & $\begin{array}{c}\text { Percentage } \\
\text { High risk }\end{array}$ & $\begin{array}{c}\text { Normal } \\
\text { usage group } \\
\mathbf{n = 1 2 5}\end{array}$ & $\begin{array}{c}\text { Percentage } \\
\text { Normal usage }\end{array}$ \\
\hline $\begin{array}{c}\text { Less than or } \\
\text { equal to 2hrs }\end{array}$ & 20 & $10.9 \%$ & 25 & $20 \%$ \\
\hline 2-5hrs & 80 & $43.5 \%$ & 76 & $60.8 \%$ \\
\hline $\begin{array}{c}\text { More than } \\
\text { 5hrs }\end{array}$ & 84 & $45.6 \%$ & 24 & $19.2 \%$ \\
\hline
\end{tabular}

\begin{tabular}{|c|c|c|c|c|}
\hline $\begin{array}{c}\text { No of hours spent on } \\
\text { online classes }\end{array}$ & $\begin{array}{c}\text { Percentage } \\
\text { High risk }\end{array}$ & & $\begin{array}{c}\text { Percentage } \\
\text { Normal usage }\end{array}$ \\
\hline $2-3 \mathrm{hrs}$ & 62 & $33.72 \%$ & 44 & $35.2 \%$ \\
\hline $4-5 \mathrm{hrs}$ & 51 & $27.7 \%$ & 26 & $20.8 \%$ \\
\hline $6-7 \mathrm{hrs}$ & 21 & $11.41 \%$ & 07 & $5.6 \%$ \\
\hline No online classes & 50 & $27.17 \%$ & 48 & $38.4 \%$ \\
\hline
\end{tabular}

Table 6: Purpose of usage

\begin{tabular}{|c|c|c|c|c|}
\hline Purpose & $\begin{array}{c}\text { High risk } \\
\text { group } \\
\text { n= 184 }\end{array}$ & Percentage & $\begin{array}{c}\text { Normal } \\
\text { usage group } \\
\text { n= 125 }\end{array}$ & Percentage \\
\hline $\begin{array}{c}\text { Phone } \\
\text { calls/Messaging }\end{array}$ & 150 & $81.5 \%$ & 90 & $72 \%$ \\
\hline $\begin{array}{c}\text { Learning and } \\
\text { browsing }\end{array}$ & 137 & $74.4 \%$ & 96 & $76.8 \%$ \\
\hline $\begin{array}{c}\text { Gaming and } \\
\text { entertainment }\end{array}$ & 119 & $64.6 \%$ & 71 & $56.8 \%$ \\
\hline $\begin{array}{c}\text { Shopping and } \\
\text { banking }\end{array}$ & 84 & $45.6 \%$ & 51 & $40.8 \%$ \\
\hline Social media & 140 & $76.08 \%$ & 81 & $64.8 \%$ \\
\hline
\end{tabular}

Table 7: Impact on activities of daily living

\begin{tabular}{|c|c|c|c|c|}
\hline Impact & $\begin{array}{c}\text { High risk } \\
\text { group } \\
\mathbf{n = 1 8 5}\end{array}$ & Percentage & $\begin{array}{c}\text { Normal } \\
\text { usage group } \\
\text { n = 124 }\end{array}$ & Percentage \\
\hline $\begin{array}{c}\text { Decreased } \\
\text { productivity }\end{array}$ & 143 & $77.29 \%$ & 43 & $34.6 \%$ \\
\hline $\begin{array}{c}\text { Change in sleep } \\
\text { pattern }\end{array}$ & 103 & $55.67 \%$ & 21 & $16.9 \%$ \\
\hline $\begin{array}{c}\text { Urge to check } \\
\text { the message }\end{array}$ & 139 & $75.1 \%$ & 35 & $28.2 \%$ \\
\hline
\end{tabular}

Regarding the impact on daily living, the high-risk group complained of decreased productivity, change in sleep pattern, urge to check the message more $[77.9 \%, 55.67 \%$, $75.1 \%$ ] compared to normal usage group [34.6\%, $16.9 \%$, $28.2 \%$ respectively].

Table 8: Impact of Smart phone usage on Physical and Psychological Health

\begin{tabular}{|c|c|c|c|c|c|c|c|c|}
\hline Impact & High risk group n= 185 & Males & Female & Normal usage group n= 124 & Male & $\begin{array}{c}\text { Female } \\
\text { Total n =309 } \\
\text { (High risk+ normal) }\end{array}$ \\
\hline Physical \\
\hline Eyestrain & 108 & 35 & 73 & 52 & 16 & 36 & 160 \\
\hline No discomforts & 41 & 27 & 14 & 53 & 18 & 35 & 94 \\
\hline
\end{tabular}




\begin{tabular}{|c|c|c|c|c|c|c|c|}
\hline Headache & 80 & 20 & 60 & 24 & 05 & 19 & 104 \\
\hline Neck pain & 64 & 23 & 41 & 20 & 03 & 17 & 84 \\
\hline Visual disturbance & 35 & 09 & 26 & 11 & 03 & 08 & 46 \\
\hline
\end{tabular}

\begin{tabular}{|c|c|c|c|c|c|c|c|}
\hline Psychological & High risk & Males & Females & Normal & Male & Female & Total (High risk +normal) \\
\hline Anger and irritable & 51 & 16 & 35 & 13 & 6 & 7 & 64 \\
\hline Tense and anxious & 66 & 24 & 42 & 19 & 11 & 8 & 85 \\
\hline Restlessness & 46 & 16 & 30 & 12 & 05 & 7 & 58 \\
\hline Sad, feels like crying & 30 & 10 & 20 & 12 & 04 & 9 & 42 \\
\hline None and others & 75 & 28 & 47 & 66 & 23 & 43 & 141 \\
\hline Lack of concentration & 70 & 26 & 44 & 14 & 06 & 08 & 84 \\
\hline
\end{tabular}
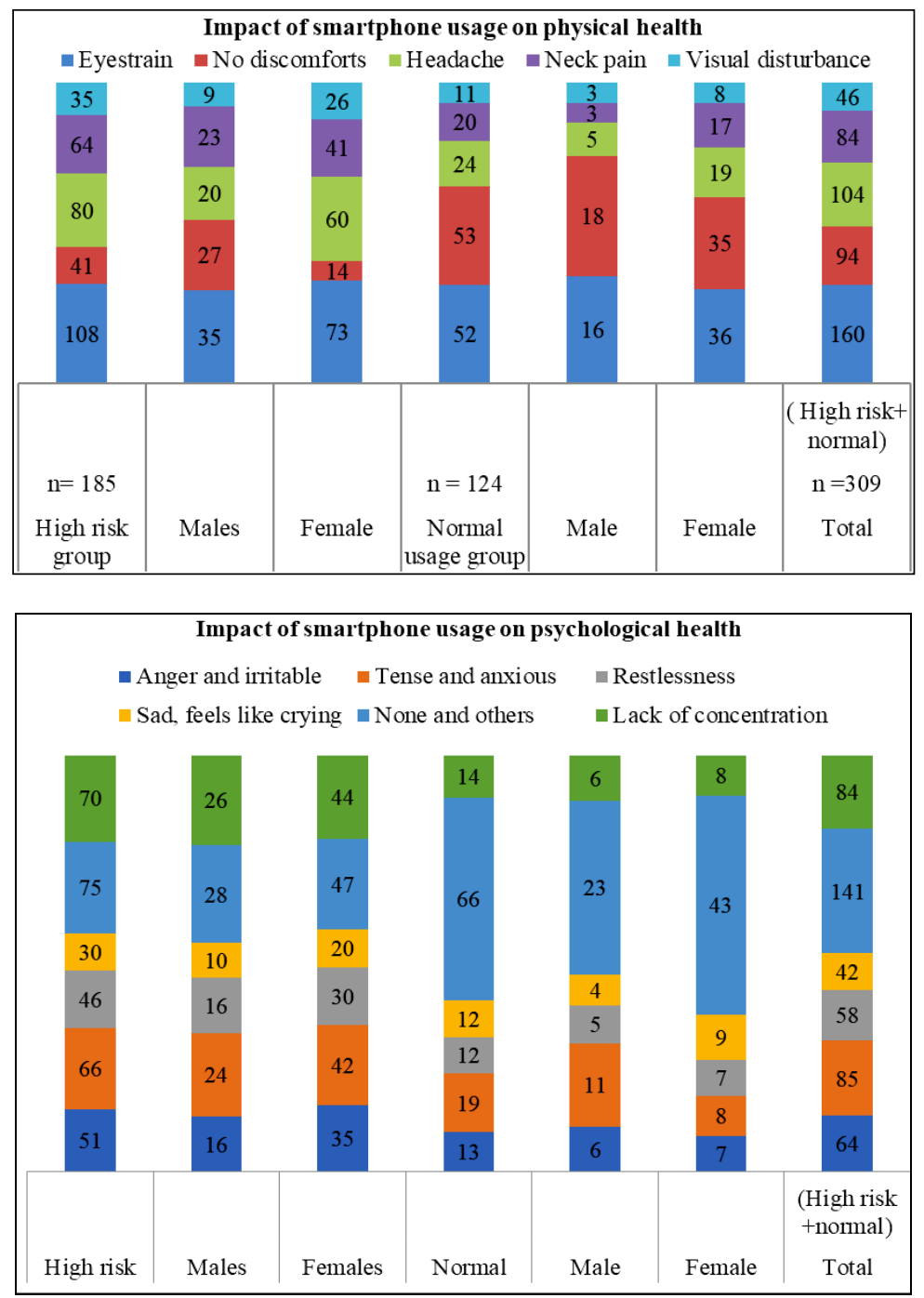

Table 9: Chi-square analysis for physical strain and sex of high-risk group

\begin{tabular}{|c|c|c|c|c|c|}
\hline \multirow{2}{*}{ Physical } & \multicolumn{2}{|c|}{ High Risk } & \multirow{2}{*}{ Total } & \multirow[t]{8}{*}{ Chi-Square Value } & P-Value \\
\hline & Male & Female & & & \multirow{7}{*}{$<0.0001$} \\
\hline Eye Strain & 35 & 73 & 108 & & \\
\hline Discomforts & 27 & 14 & 41 & & \\
\hline Headache & 20 & 60 & 80 & & \\
\hline Neck Pain & 23 & 41 & 64 & & \\
\hline Visual Disturbance & 9 & 26 & 35 & & \\
\hline Total & 114 & 214 & 328 & & \\
\hline
\end{tabular}

H0: There is no association between physical strain and sex among smart phone users belonging to high-risk category.

H1: There is an association between physical strain and sex among smart phone users belonging to high-risk category.

Conclusion: Since Chi-Square calculated is 22.41 which is much greater than tabled value of Chi-Square (i.e., 13.27) at one percent level of significance for 4 degrees of freedom, hence $\mathrm{HO}$ is rejected. Indicating that there is an association between the types of physical strain and the sex. i.e., vulnerable group seems to be women (65\%). Concluding that women are more probable to be effected physically than men when used smart phones during Covid Pandemic. 
Table 10: Chi-Square Analysis for Physical Strain and Sex of Normal Usage Group

\begin{tabular}{|c|c|c|c|c|c|}
\hline \multirow{2}{*}{ Physical } & \multicolumn{2}{|c|}{ Normal usage Group } & Total & $\begin{array}{c}\text { Chi-Square } \\
\text { Value }\end{array}$ & $\begin{array}{c}\text { P- } \\
\text { Value }\end{array}$ \\
\cline { 2 - 4 } & Male & Female & & 52 & \\
\\
\hline Eye Strain & 16 & 36 & 52 & \\
\hline Discomforts & 18 & 35 & 53 & & \\
\hline Headache & 5 & 19 & 24 & \multirow{2}{*}{3.41} & $<0.10$ \\
\hline Neck Pain & 3 & 17 & 20 & & \\
\hline Visual Disturbance & 3 & 8 & 11 & & \\
\hline Total & 45 & 115 & 160 & & \\
\hline
\end{tabular}

H0: There is no association between physical strain and sex among smart phone users belonging normal usage category during Covid Pandemic.

H1: There is an association between physical strain and sex among smart phone users belonging to normal usage category.

Conclusion: Since Chi-Square calculated is 3.41 which is smaller than tabled value of Chi-Square (i.e., 9.488) at five per cent level of significance for 4 degrees of freedom, hence $\mathrm{H} 0$ is accepted. Indicating that there is no association between the types of physical strain and the sex.

Table 11: Chi-Square Analysis for Physical Strain and Different Risk Categories

\begin{tabular}{|c|c|c|c|c|c|}
\hline \multirow{2}{*}{ Physical } & \multicolumn{2}{|c|}{ Risk Categories } & \multirow{2}{*}{ Total } & \multirow{2}{*}{$\begin{array}{c}\text { Chi-Square } \\
\text { Value }\end{array}$} & \multirow{2}{*}{$\begin{array}{c}\text { P- } \\
\text { Value }\end{array}$} \\
\hline & High & Normal & & & \\
\hline Eye Strain & 108 & 52 & 160 & \multirow{6}{*}{32.92} & \multirow{6}{*}{$<0.001$} \\
\hline Discomforts & 41 & 53 & 94 & & \\
\hline Headache & 80 & 24 & 104 & & \\
\hline Neck Pain & 64 & 20 & 84 & & \\
\hline Visual Disturbance & 35 & 11 & 46 & & \\
\hline \begin{tabular}{|c|} 
Total \\
\end{tabular} & 328 & 160 & 488 & & \\
\hline
\end{tabular}

H0: There is no association between physical strain and sex among smart phone users belonging normal usage category during Covid Pandemic.

H1: There is an association between physical strain and sex among smart phone users belonging to normal usage category.

Conclusion: Since Chi-Square calculated is 32.92 which is much higher than tabled value of Chi-Square (i.e., 13.277) at one per cent level of significance for 4 degrees of freedom, hence $\mathrm{HO}$ is rejected. Indicating that there is an association between the types of physical strain and risk categories i.e., vulnerable group seems to be of high-risk category representing $67 \%$. Concluding that mobile users are more probable to be effected physically with high risk compared to normal usage group.

Table 12: Chi-Square Analysis for Psychological Factors and Sex among High-Risk Group of Smart Phone Users

\begin{tabular}{|c|c|c|c|c|c|}
\hline \multirow{2}{*}{ Psychological } & \multicolumn{2}{|c|}{ High Risk } & Total & $\begin{array}{c}\text { Chi-Square } \\
\text { Value }\end{array}$ & $\begin{array}{c}\text { P- } \\
\text { Value }\end{array}$ \\
\cline { 2 - 4 } & Male & Female & & & \\
\hline Anger \& Irritation & 16 & 35 & 51 & & \\
\hline Tense and Anxiety & 24 & 42 & 66 & & \\
\hline Restlessness & 16 & 30 & 46 & \multirow{2}{*}{0.67} & $<0.95$ \\
\cline { 1 - 3 } Sad, Feels like Crying & 10 & 20 & 30 & & \\
\hline None \& Others & 28 & 47 & 75 & & \\
\hline Lack of Concentration & 26 & 44 & 70 & & \\
\hline Total & 120 & 218 & 338 & & \\
\hline
\end{tabular}

H0: There is no association between psychological factors and sex among high-risk group of smart phone users.

H1: There is an association between psychological factors and sex among high-risk group of smart phone users.
Conclusion: Since Chi-Square calculated is 0.67 which is much less than tabled value of Chi-Square (i.e., 0.831) at ninety-seven per cent level of significance for 5 degrees of freedom, hence $\mathrm{H} 0$ is accepted. Indicating that there is no association between the types of psychological factors and sex among high-risk group.

Table 13: Chi-Square Analysis for Psychological Factors and Sex among Normal Risk Group of Smart Phone Users

\begin{tabular}{|c|c|c|c|c|c|}
\hline \multirow{2}{*}{ Psychological } & \multicolumn{2}{|c|}{ Normal Risk } & Total & $\begin{array}{c}\text { Chi-Square } \\
\text { Value }\end{array}$ & $\begin{array}{c}\text { P- } \\
\text { Value }\end{array}$ \\
\cline { 2 - 4 } & Male Female & & & \\
\hline Anger \& Irritation & 6 & 7 & 13 & & \\
\hline Tense and Anxiety & 11 & 8 & 19 & \multirow{2}{*}{3.99} & $<0.05$ \\
\hline Restlessness & 5 & 7 & 12 & \\
\hline Sad, Feels like Crying & 4 & 9 & 13 & & \\
\hline None \& Others & 23 & 43 & 66 & & \\
\hline Lack of Concentration & 6 & 8 & 14 & & \\
\hline Total & 55 & 82 & 137 & & \\
\hline
\end{tabular}

H0: There is no association between psychological factors and sex among normal risk group of smart phone users.

H1: There is an association between psychological factors and sex among normal risk group of smart phone users.

Conclusion: Since Chi-Square calculated is 3.99 which is much lesser than tabled value of Chi-Square (i.e., 11.07) at five per cent level of significance for 5 degrees of freedom, hence $\mathrm{HO}$ is accepted, indicating that there is no association between the types of psychological factors and sex among normal risk group.

Table 14: Chi-Square Analysis for Psychological Factors and Different Risk Categories

\begin{tabular}{|c|c|c|c|c|c|}
\hline \multirow{2}{*}{ Psychological } & \multicolumn{2}{|c|}{ Risk Categories } & Total & $\begin{array}{c}\text { Chi-Square } \\
\text { Value }\end{array}$ & $\begin{array}{c}\text { P- } \\
\text { Value }\end{array}$ \\
\cline { 2 - 4 } & High & Normal & & & \\
\hline Anger \& Irritation & 51 & 13 & 64 & & \\
\hline Tense and Anxiety & 66 & 19 & 85 & & \\
\hline Restlessness & 46 & 12 & 58 & \multirow{2}{*}{34.18} & $<0.001$ \\
\hline Sad, Feels like Crying & 30 & 13 & 43 & \\
\hline None \& Others & 75 & 66 & 141 & & \\
\hline Lack of Concentration & 70 & 14 & 84 & & \\
\hline Total & 338 & 137 & 475 & & \\
\hline
\end{tabular}

H0: There is no association between psychological factors and risk levels smart phone users during Covid Pandemic.

H1: There is an association between psychological factors and risk levels smart phone users during Covid Pandemic.

Conclusion: Since Chi-Square calculated is 34.18 which are much higher than tabled value of Chi-Square (i.e., 15.08) at one per cent level of significance for 5 degrees of freedom, hence $\mathrm{H} 0$ is rejected. Indicating that there is an association between the psychological factors types and risk categories i.e., vulnerable group seems to be of high risk category representing $71 \%$. Concluding that mobile users are more probable to be effected psychologically with high risk compared to normal usage group.

\section{Discussion}

Excessive smartphone usage is a common problem among adults worldwide. And the usage has increased during COVID Pandemic. However, many people fail to realize that they have addiction to smartphone and it is a serious issue that can have a negative effect on the person's physical and psychological health. 
Addiction is a disorder with severe effects on physical and psychological health. Behaviour may have a similar presentation as addiction in terms of excessive use, impulse control problems, and negative consequences, but that does not mean that it should be considered an addiction ${ }^{[4]}$. When studying technological behaviours using other terms such as "problematic use" or excessive use are more appropriate. So here the term excessive usage has been used.

This study aimed at finding the prevalence of smartphone usage among males and females, studying the demographic characteristics, level of usage, purpose of usage, impact of lockdown on smartphone use and the impact on physical and psychological health. The smartphone has become an essential part of daily life and the attachment to smartphone was assessed by questioning about the urge to check the phone, sleeping with phone under the pillow and loosing track of time while using the same with positive responses. Contrary to our expectation, $84 \%$ of the participants responded positively for spending quality time with family and that is the measure they are taking to reduce smartphone usage.

Statistical analysis showed the positive association between high-risk group and Physical and psychological impact, women being more vulnerable for physical strain.

\subsection{Limitations}

Some variables were measured subjectively, using simple questions without using standardized scales.

Self-reported data and actual smartphone use data could provide a comprehensive explanation about smartphone usage patterns.

A survey during the non-covid period would have given a better comparison of data and increase in smartphone usage during lockdown in true sense.

\section{Conclusion}

This study showed that the prevalence of smart phone usage was high among females [63.4\%] than males [36.60\%].

The causes of over use of smart phone are fairly general and vary from person to person. The impacts are also person dependent. The study identified that $59.5 \%$ of users are at a high risk, and $40.4 \% \%$ are normal usage group. This percentage vary largely based on the region of study and age group and time of study. On analysing the duration and event of usage of mobile phones, it was found that the phone was maximum used for social networking, phone calls/messaging, online classes.

Chi-square analysis for physical strain and sex of high-risk group indicated that there is an association between the types of physical strain and the sex. i.e., vulnerable group seems to be women (65\%). Chi-square analysis for physical strain and different risk categories indicated that the mobile users are more probable to be effected physically with high risk [67\%] compared to normal usage group.

Chi-square analysis for psychological factors and sex among high-risk group of smart phone users indicated that there is no association between the types of psychological factors and sex among high-risk group. Chi-square analysis for psychological factors and different risk categories indicated that mobile users are more probable to be effected psychologically with high risk [71\%] compared to normal usage group.

Acknowledgement: Dr. S.B. Madagi, Former Professor, Dept. of Bioinformatics, Biotechnology, Mathematics, Statistics and Zoology, Karnataka State Akkamahadevi Women's University, Vijayapura.

Conflict of interest: The authors declare no conflict of interest.

\section{References}

1. Al-Barashdi HS, Bouazza A, Al Zubaidi A. Psychometric Properties of Smartphone Addiction Questionnaire (SPAQ) among Sultan Qaboos University Undergraduate Students. Journal of Educaional \& Psychological Studies (JEPS) 2014;8(4):637.

2. Cha SS, Seo BK. Smartphone use and smartphone addiction in middle school students in Korea: Prevalence, social networking service, and game use. Health Psychology Open. 2018, 5(1):2055102918755046.

$10.1177 / 2055102918755046$.

3. Reddy Naik, Sk Kiran \& Js Sanjana. "Mobile Phone Addiction: Symptoms, Impacts and Causes-A Review." Conference paper 2019.

4. Panova $\mathrm{T}, \&$ Carbonell $\mathrm{X}$. Is smartphone addiction really an addiction? Journal of Behavioral Addictions 2018;7: 252-259. https://doi.org/10.1556/2006.7.2018.49

5. ETTelecom, July 09, 2020 India to have 820 million smartphone users by 2022, Telecom News, (indiatimes.com).

6. Aman Kr. Singh, Ashish Kr. Prajapati, Vikash Kumar, Subhankar Mishra, Usage Analysis of Mobile Devices, Procedia Computer Science 2017;122:657-662. ISSN 1877-0509,https://doi.org/10.1016/j.procs.2017.11.420.

7. Arora Nisha, Singh Neetu \& Taneja Parvesh. Smart Phone usage Pattern: A Study of College Students. International Journal of Knowledge Management and Practices 2016;4:31-36.

8. Oxford advanced dictionary, oxford university press, OxfordLearnersDictionaries.com.

9. Sehar Shoukat. Cell phone addiction and psychological and physiological health in adolescents, Excli Journal, PMCID: PMC6449671, PMID: 30956638. 2019.

10. Ellish Duke, Christian Montag. Smartphone addiction, daily interruptions and self-reported productivity, Addictive Behaviors Reports, 2017;6:90-95.

11. Rebecca Joy Stanborough, MFA. How to tell if you could be addicted to your phone, healthline. 2019.

12. Sanjeev Davey, Anuradha Davey. Assessment of smartphone addiction in Indian adolescents: a mixed method study by systematic-review and meta-analysis approach, international journal of preventive medicine, PMCID: PMC4336980. 2014.

13. Nazir S. Hawi, Maya Samaha. relationships among smartphone addiction, anxiety and family relations, Behaviour and Information Technology. 2017;36(10):1046-1052.

\section{Annexure}

Table 1: Frequently used apps

\begin{tabular}{|c|c|c|c|}
\hline \multicolumn{4}{|c|}{ Frequently used apps in smart phone } \\
\hline Sl. No. & Apps & No's & Percentage \\
\hline 1. & WhatsApp & 132 & $42.71 \%$ \\
\hline 2. & YouTube & 52 & $17 \%$ \\
\hline 3. & Amazon & 4 & $1.29 \%$ \\
\hline 4. & Facebook & 12 & $4 \%$ \\
\hline 5. & Instagram & 77 & $25 \%$ \\
\hline 6. & Goggle & 27 & $9 \%$ \\
\hline 7. & Zoom & 36 & $12 \%$ \\
\hline 8. & Pubg & 8 & $2.58 \%$ \\
\hline
\end{tabular}




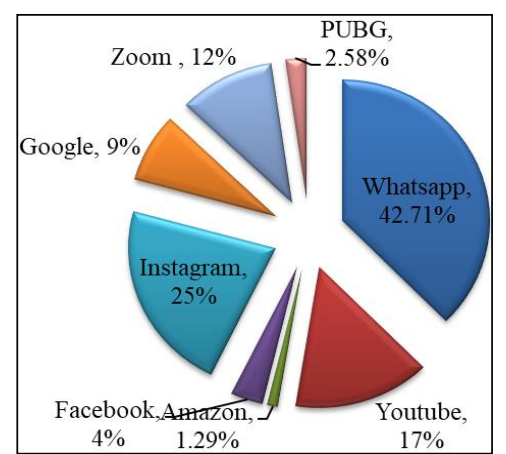

Table 2: Usage of smartphones for online classes

\begin{tabular}{|c|c|c|c|}
\hline \multicolumn{4}{|c|}{ Using smart phone for online classes, a burden } \\
\hline Sl. No & A Burden & No's & Percentage \\
\hline 1 & Yes & 154 & $50 \%$ \\
\hline 2 & No & 90 & $29 \%$ \\
\hline 3 & No online classes & 65 & $21 \%$ \\
\hline & Total & 309 & \\
\hline
\end{tabular}

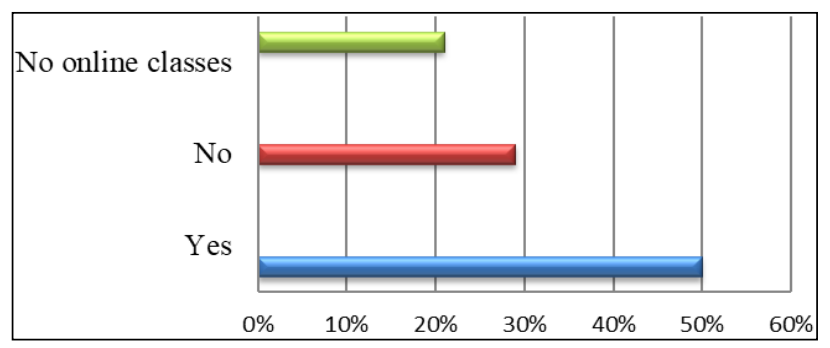

Fig 2: Using smartphones for online classes, a burden

Table 3: No of hours spent on online classes

\begin{tabular}{|c|c|c|c|}
\hline Sl. No. & Time Spent & No's & Percentage \\
\hline 1. & $2-3 \mathrm{hrs}$ & 106 & $34 \%$ \\
\hline 2. & $4-5 \mathrm{hrs}$ & 76 & $25 \%$ \\
\hline 3. & $6-7 \mathrm{hrs}$ & 28 & $9 \%$ \\
\hline 4. & No online classes & 99 & $32 \%$ \\
\hline & Total & 309 & \\
\hline
\end{tabular}

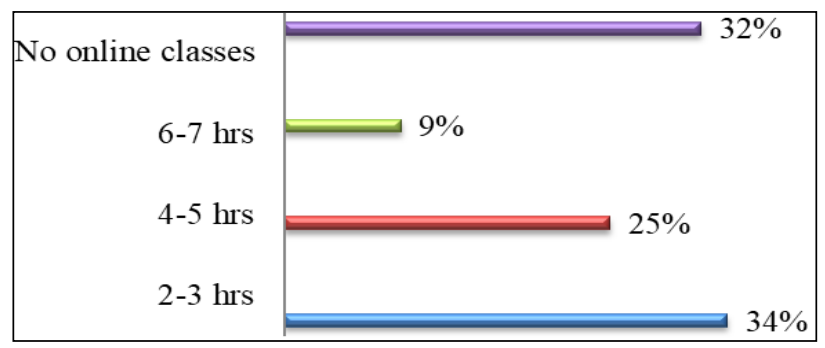

Fig 3: No of hours spent on online classes

Table 4: Sleeping with smartphone under the pillow

\begin{tabular}{|c|c|c|c|}
\hline \multicolumn{4}{|c|}{ Sleeping with smart phone under pillow } \\
\hline Sl. No. & Sleep with phone & No's & Percentage \\
\hline 1. & Yes & 157 & $51 \%$ \\
\hline 2. & No & 152 & $49 \%$ \\
\hline & Total & 309 & \\
\hline
\end{tabular}

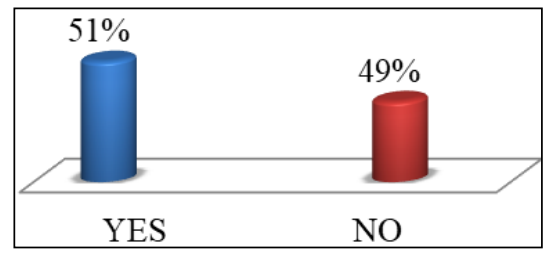

Fig 4: Sleeping with smartphone under the pillow
Table 5: Hours of sleep

\begin{tabular}{|c|c|c|c|}
\hline Sl. No. & Hours of sleep & No's & Percentage \\
\hline 1. & $8-9 \mathrm{hrs}$ & 143 & $46.27 \%$ \\
\hline 2. & $5-7 \mathrm{hrs}$ & 149 & $48 \%$ \\
\hline 3. & $3-5 \mathrm{hrs}$ & 16 & $5.17 \%$ \\
\hline 4. & $<3 \mathrm{hrs}$ & 1 & $0.32 \%$ \\
\hline & Total & 309 & \\
\hline
\end{tabular}

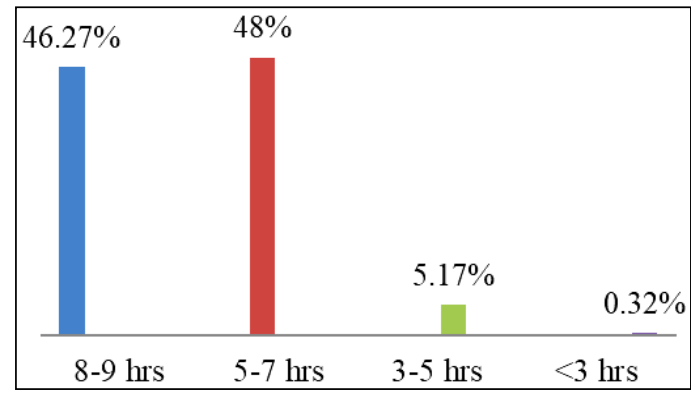

Fig 5: Hours of sleep

Table 6: Change in sleep pattern

\begin{tabular}{|c|c|c|c|}
\hline \multicolumn{4}{|c|}{ Change in sleep pattern } \\
\hline Sl. No. & Any changes & No's & Percentage \\
\hline 1. & Yes & 124 & $40 \%$ \\
\hline 2. & No & 185 & $60 \%$ \\
\hline & Total & 309 & \\
\hline
\end{tabular}

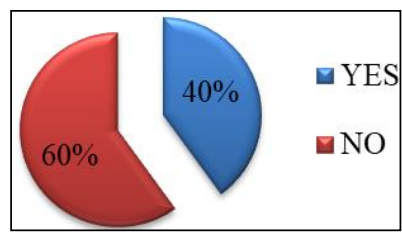

Fig 6: Change in sleep patterns

Table 7: Usage of phone to view calls/messages always

\begin{tabular}{|c|c|c|c|}
\hline \multicolumn{4}{|c|}{ Usage of phone to view, calls/message always } \\
\hline Sl. No & Used to view & No's & Percentage \\
\hline 1. & Yes & 182 & $59 \%$ \\
\hline 2. & No & 127 & $41 \%$ \\
\hline & Total & 309 & \\
\hline
\end{tabular}

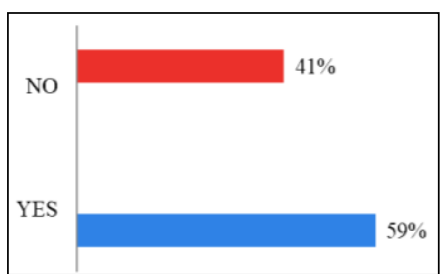

Fig 7: Usage of phone to view calls/messages always

Table 8: Feeling of decreased productivity

\begin{tabular}{|c|c|c|c|}
\hline \multicolumn{4}{|c|}{ Feeling of decreased productivity } \\
\hline Sl. No. & Reduced productivity & No's & Percentage \\
\hline 1. & Yes & 245 & $79 \%$ \\
\hline 2. & No & 64 & $21 \%$ \\
\hline & Total & 309 & \\
\hline
\end{tabular}




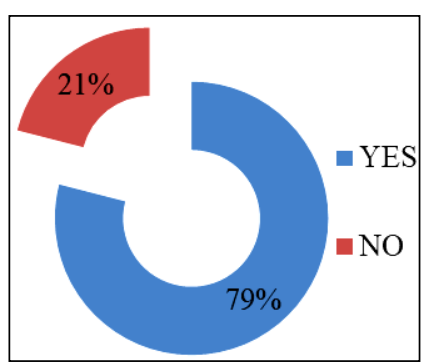

Fig 8: Decreased productivity

Table 9: Usage of smartphone while eating

\begin{tabular}{|c|c|c|c|}
\hline \multicolumn{4}{|c|}{ Watching smartphone while eating } \\
\hline Sl. No. & While eating & No's & Percentage \\
\hline 1 & Yes & 88 & $28 \%$ \\
\hline 2 & NO & 221 & $72 \%$ \\
\hline & Total & 309 & \\
\hline
\end{tabular}

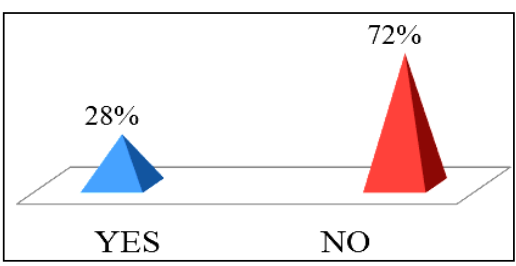

Fig 9: Usage of smartphone while eating

Table 10: Spending quality time with family and friends

\begin{tabular}{|c|c|c|c|}
\hline \multicolumn{4}{|c|}{ Spending quality time with family and friends } \\
\hline Sl. No. & Spending quality time & No's & Percentage \\
\hline 1 & Yes, I spend enough time & 258 & $83 \%$ \\
\hline 2 & Yes, I try hard to spend & 46 & $15 \%$ \\
\hline 3 & No, I don't spend & 5 & $2 \%$ \\
\hline & Total & 309 & \\
\hline
\end{tabular}

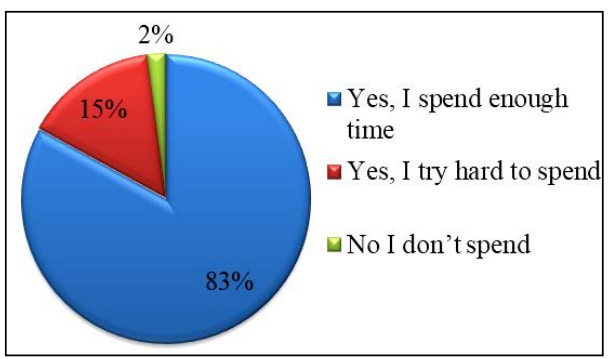

Fig 10: Spending quality time with family and friends

Table 11: Able to concentrate on work and stay active after smartphone usage

\begin{tabular}{|c|c|c|c|}
\hline \multicolumn{4}{|c|}{ Able to concentrate and stay active after smartphone usage } \\
\hline Sl. No. & Able to be active & No's & Percentage \\
\hline 1. & Yes & 225 & $73 \%$ \\
\hline 2. & No & 84 & $27 \%$ \\
\hline & Total & 309 & \\
\hline
\end{tabular}

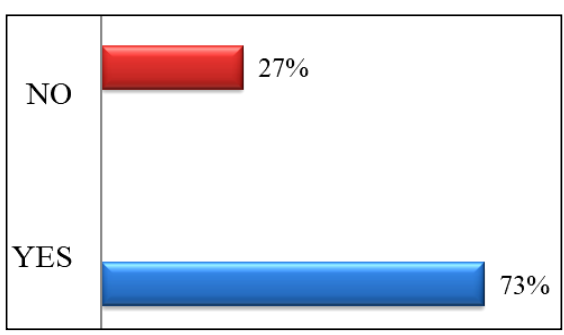

Fig 11: Able to concentrate on work and stay active after smartphone usage
Table 12: Loosing track of time while using a smartphone

\begin{tabular}{|c|c|c|c|}
\hline \multicolumn{4}{|c|}{ Loosing track of time while using a smartphone } \\
\hline Sl. No. & Loosing time & No's & Percentage \\
\hline 1. & Yes & 182 & $59 \%$ \\
\hline 2. & No & 127 & $41 \%$ \\
\hline & Total & 309 & \\
\hline
\end{tabular}

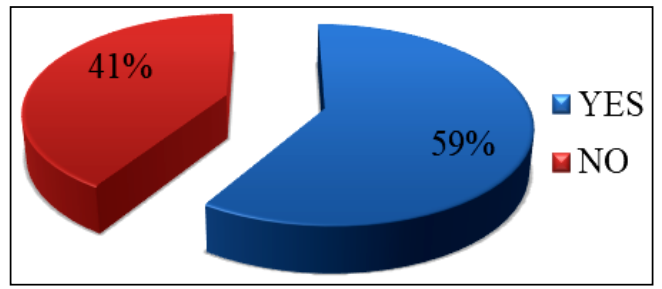

Fig 12: Loosing track of time while using a smartphone

Table 13: Effect of lockdown due to pandemic on smartphone usage

\begin{tabular}{|c|c|c|c|}
\hline \multicolumn{4}{|c|}{ Effect of lockdown on smartphone usage } \\
\hline Sl. No. & Lockdown effect & No's & Percentage \\
\hline 1 & Yes & 245 & $79 \%$ \\
\hline 2 & No & 64 & $21 \%$ \\
\hline & Total & 309 & \\
\hline
\end{tabular}

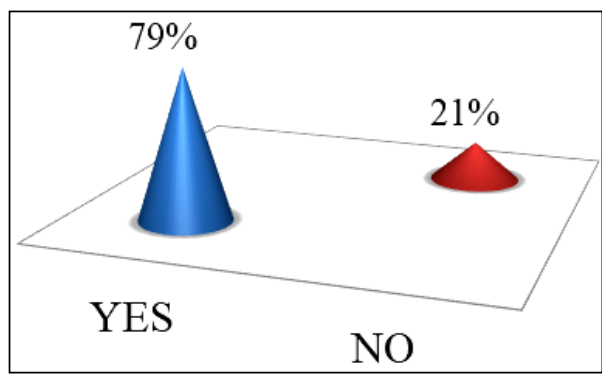

Fig 13: Has lockdown due to pandemic affected the usage of smartphone?

Table 14: Measures taken to reduce the usage of smartphone

\begin{tabular}{|c|c|c|c|}
\hline \multicolumn{5}{|c|}{ Measures taken to reduce smart phone usage } \\
\hline Sl. No. & Measures taken & No's & Percentage \\
\hline 1 & Switch off/flight mode & 1 & $0 \%$ \\
\hline 2 & Recreational activities & 150 & $49 \%$ \\
\hline 3 & Spending time with family & 190 & $61 \%$ \\
\hline 4 & Never consider to reduce usage & 40 & $12.90 \%$ \\
\hline 5 & Others & 19 & $6.10 \%$ \\
\hline
\end{tabular}

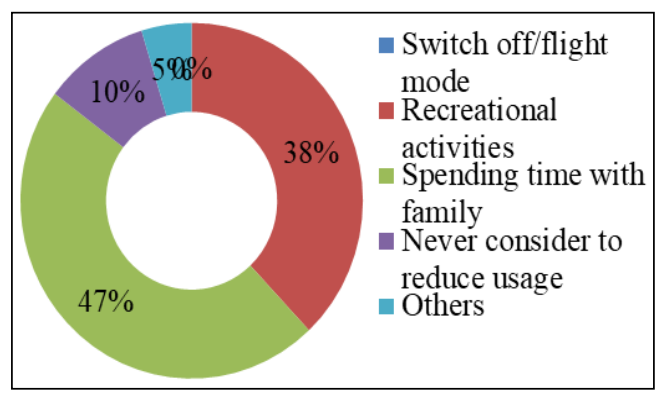

Fig 14: Measures taken to reduce smartphone usage 